\title{
Chronic thoracoabdominal aortic dissection: endovascular options to obliterate the false lumen
}

\author{
Patrick R. Vargo, Jean-Luc Maigrot, Eric E. Roselli \\ Department of Thoracic and Cardiovascular Surgery, Aorta Center, Heart and Vascular Institute, Cleveland Clinic, Cleveland, Ohio, USA \\ Correspondence to: Eric E. Roselli, MD. Department of Thoracic and Cardiovascular Surgery, Cleveland Clinic, 9500 Euclid Avenue, J4-1, Cleveland, \\ OH, USA. Email: RosellE@ccf.org.
}

Background: Persistent false lumen patency in chronic thoracoabdominal aortic dissections after thoracic
endovascular aortic repair (TEVAR) contributes to negative aortic remodeling. We have previously described
the evolution of various endovascular techniques to treat persistent false lumen perfusion including false
lumen embolization. Objectives of this study are to describe endovascular techniques to obliterate the false
lumen and present updated outcomes in a recent series of patients undergoing false lumen embolization for
chronic aortic dissection.

Methods: From January 2018 to May 2021, 17 patients with chronic dissection underwent false lumen embolization with coils, iliac plugs, and nitinol plugs. This was often in conjunction with or following TEVAR and balloon fracture fenestration. Mean follow-up 354 324 days.

Results: After false lumen embolization there was no mortality, stroke, spinal cord ischemia, or visceral and limb ischemia. No patients required dialysis, though 1 (5.9\%) did experience acute kidney injury. There was $1(5.9 \%)$ patient that required endovascular re-intervention on the thoracoabdominal aorta. No patients underwent subsequent open surgical repair.

Conclusions: TEVAR with adjunctive false lumen embolization and balloon fracture fenestration are techniques to obliterate retrograde flow into the false lumen of chronic thoracoabdominal aortic dissections in appropriately selected patients.

Keywords: Aortic dissection; endovascular; false lumen; embolization; aneurysm

Submitted Sep 02, 2021. Accepted for publication Oct 13, 2021.

doi: 10.21037/acs-2021-taes-23

View this article at: https://dx.doi.org/10.21037/acs-2021-taes-23

\section{Introduction}

Thoracic endovascular aortic repair (TEVAR) has become an integral and well tolerated intervention for thoracoabdominal aortic dissection, but persistent false lumen patency represents a mode of treatment failure and is associated with poor long-term outcomes $(1,2)$. Though proximal entry tears in the thoracic aorta may be covered by endografts, total thrombosis of the false lumen is achieved only in a minority of patients (3). Continued false lumen patency results in aneurysmal degeneration and risk of aortic rupture requiring additional reinterventions (4-7). Conversely, thrombosis of the false lumen is an independent predictor of aortic positive remodeling $(8,9)$.

In chronic thoracoabdominal aortic dissections the false lumen is often still pressurized by retrograde false lumen flow alongside the stented true lumen of the aorta from distal re-entry tears and branches off the false lumen in the abdominal aorta (10). While open thoracoabdominal aortic repair may be durable, it also carries with it significant morbidity and mortality (11-13). Various endovascular techniques to treat persistent false lumen perfusion including false lumen embolization (FLE) have been previously described. Over the last decade, patient selection and surgical techniques have evolved. The purpose of this study is to characterize endovascular adjuncts used to obliterate the false lumen of chronic aortic dissections and present updated outcomes in a recent series of patients undergoing FLE for chronic aortic dissection. 


\begin{tabular}{|ll}
\hline Table 1 Patient demographics & Result $(\mathrm{n}=17)$ \\
\hline Variable & $57 \pm 8.8$ \\
\hline Age (years) & $13[76]$ \\
\hline Male & $5[29]$ \\
\hline Connective tissue disease & $10[59]$ \\
\hline Residual chronic DeBakey I dissection & $7[41]$ \\
\hline Chronic DeBakey Illb dissection & $17[100]$ \\
\hline Prior aortic procedure & $10[59]$ \\
\hline Previous type A dissection repair & $13[76]$ \\
\hline Prior TEVAR & $4[24]$ \\
\hline Prior PETTICOAT dissection stent & $11[65]$ \\
\hline Prior balloon fracture fenestration & TEVAR, thoracic \\
\hline $\begin{array}{l}\text { Values presented as mean } \pm \text { SD or } n \text { [\%]. } \\
\text { endovascular aortic repair; PETTICOAT, provisional extension to }\end{array}$ \\
induce complete attachment.
\end{tabular}

\section{Methods}

\section{Patients}

The study was approved by the institutional review board at our institution and informed consent was waived. From January 1st 2018 to May 1st 2021, 17 patients underwent FLE procedures at our institution. Mean age was $57 \pm$ 8.8 years, and 13 (76\%) of patients were male. Ten (58.8\%) patients had chronic, DeBakey type I dissection with residual thoracoabdominal dissection after ascending and arch repair, including frozen elephant trunk in 9 (90\%). The other seven (41.2\%) had DeBakey type IIIB dissections. Five patients (29.4\%) were known to have connective tissue disorders confirmed by genetic testing. Patient characteristics are further detailed in Table 1.

\section{Surgical technique and interventions}

The operative techniques of FLE and Balloon Fracture Fenestration (BFF) for false lumen obliteration in chronic dissection used at our institution have been previously described $(14,15)$. In short, following induction of general anesthesia with or without a CSF drain, intravascular ultrasound (IVUS) is used to identify and guide catheters through the desired lumen. TEVAR is performed in the true lumen, and FLE is performed after accessing the false lumen by deploying embolization devices within the distal thoracic aorta to occlude retrograde perfusion. Occasionally, prominent segmental arteries (i.e., intercostal and/or bronchial arteries) providing outflow to the retrograde perfusion are also embolized. BFF is achieved by expanding a compliant balloon (Coda, Cook Medical, Bloomington, IN, USA) within the covered thoracic endograft in the descending thoracic aorta to fracture the dissection flap and actively expand the TEVAR device. In the most recent cases since the device gained commercial approval (Cook, Bloomington, IN, USA), abdominal bare metal stenting was performed to the level of the aortic bifurcation prior to BFF. Angiography is used after device placement to confirm elimination of false lumen flow. Procedural details including devices used are presented in Table 2 .

\section{Data collection and statistical analysis}

Data were retrospectively collected from the electronic medical record. Endpoints were serious adverse complications. Stroke was defined as greater than a 24-hour new onset neurological deficit confirmed by imaging and neurology. Spinal cord ischemia was defined as temporary or permanent paraplegia post-operatively. Descriptive statistical analysis was used to analyze variables. Continuous variables are presented as median or mean \pm standard deviation, and categorical variables are presented as percentages.

\section{Results}

\section{Perioperative outcomes}

Seventeen patients underwent 18 FLE procedures, often in conjunction with TEVAR, BFF and/or abdominal bare stenting (Figure 1). Intraoperative angiography confirmed early technical success in all patients. Perioperative outcomes are shown in Table 3. There was no mortality, stroke, visceral or limb ischemia, or spinal cord ischemia. One patient experienced acute kidney injury that did not require dialysis, and another developed delirium with a negative stroke evaluation.

\section{Late outcomes and aortic reintervention}

Mean follow-up for this study was $354 \pm 324$ days. There was 1 early readmission within 30 days of discharge for chest pain, but cardio-aortic work-up was negative for acute syndromes and at a later encounter the patient underwent 


\begin{tabular}{|ll}
\hline Table 2 Procedural details & \\
\hline Variable & Values, $\mathrm{n}[\%]$ \\
\hline Concomitant TEVAR & $7[41]$ \\
\hline Isolated false lumen embolization & $10[59]$ \\
\hline Balloon fracture fenestration & $4[24]$ \\
\hline PETTICOAT dissection stent & $5[29]$ \\
\hline Iliac occluder plug & $7[41]$ \\
\hline Embolization coils & $16[94]$ \\
\hline Nitinol plug & $4[24]$ \\
\hline$>1$ device type used & $8[47]$ \\
\hline$>1$ device used & $17[100]$ \\
\hline$>1$ iliac occluder plug used & $4[24]$ \\
\hline CSF drainage used & $4[24]$ \\
\hline
\end{tabular}

TEVAR, thoracic endovascular aortic repair; PETTICOAT, provisional extension to induce complete attachment.

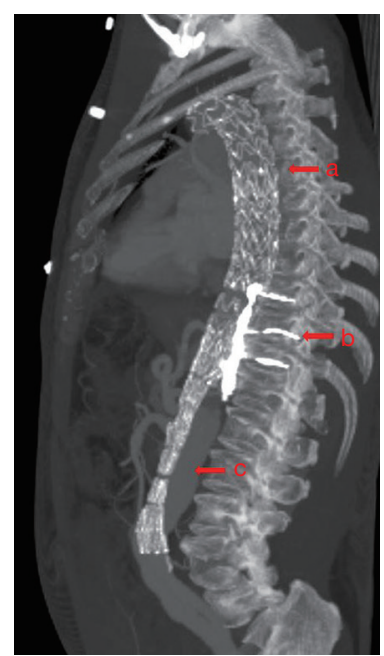

Figure 1 CT sagittal image of chronic thoracoabdominal aortic dissection treated with false lumen obliteration techniques (a) thoracic endovascular aortic repair with balloon expanded covered stents, (b) false lumen and lumbar embolization with coils, and (c) bare metal dissection stent in abdominal aorta. CT, computed tomography.

elective Bentall root replacement for aneurysm. There were 3 late readmissions occurring $>6$ months post-operatively for transient ischemia attack, congestive heart failure and enlarging thoracoabdominal aortic aneurysm. The latter

\begin{tabular}{|ll}
\hline Table 3 Postoperative outcomes & \\
\hline Variable & Outcome $(n=17)$ \\
\hline Mean follow-up time (days) & $354 \pm 324$ \\
\hline Mortality & $0(0)$ \\
\hline Stroke & $0(0)$ \\
\hline Spinal cord ischemia & $0(0)$ \\
\hline Postoperative Ml & $0(0)$ \\
\hline Postoperative dialysis & $0(0)$ \\
\hline Postoperative reintubation & $0(0)$ \\
\hline Tracheostomy & $0(0)$ \\
\hline Postoperative atrial fibrillation & $1(5.9)$ \\
\hline Postoperative endoleak & $1(5.9)$ \\
\hline 30-d readmission & $1(5.9)$ \\
\hline
\end{tabular}

Values presented as mean \pm SD or $n(\%)$.

patient underwent repeat TEVAR with bare metal extension stenting, additional FLE and femoral artery reconstruction.

\section{Discussion}

In this study we present our updated experience with TEVAR and endovascular adjuncts to obliterate the false lumen in select patients with chronic thoracoabdominal aortic dissection. These patients had complicated dissection with a suitable proximal thoracic landing zone, nonaneurysmal distal descending aorta $(<42 \mathrm{~mm})$, and were at increased risk for open thoracoabdominal aortic repair due to comorbidities. There was no mortality, spinal cord ischemia, stroke, or failed intervention requiring open aortic repair. We have previously described achieving complete false lumen thrombosis in $90 \%$ of patients after one or two rounds of FLE in 51 patients (14), consistent with similar promising outcomes reported in the literature (2,16-18).

While insertion of embolization coils and occluder plugs obstruct retrograde false lumen perfusion, another strategy to obliterate the false lumen is to Balloon Fracture Fenestrate the thickened dissection flap and achieve full expansion of the covered thoracic endograft and circumferential seal against adventitia. Positive aortic remodeling was seen in $26 \%$ of patients with TEVAR and BFF alone, without incidence of aortic rupture (15). Kölbel and colleagues observed false lumen thrombosis 


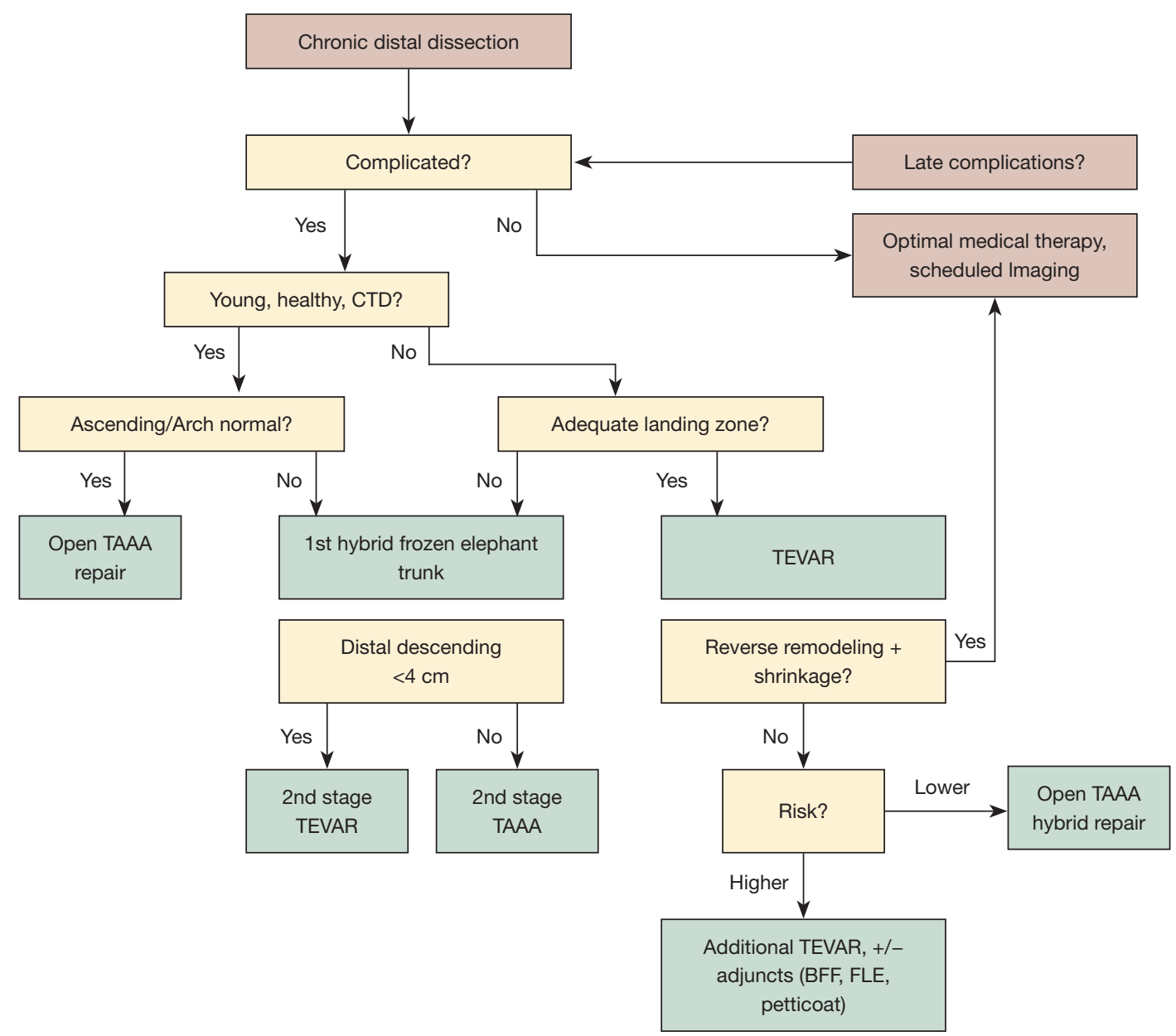

Figure 2 Representative treatment algorithm for chronic aortic dissection of the thoracoabdominal aorta as published by Miletic and colleagues (14). BFF, endovascular balloon fracture fenestration; CTD, connective tissue disease; FLE, false lumen embolization; TAAA, thoracoabdominal aortic aneurysm; TEVAR, thoracic endovascular aortic repair.

and freedom from aortic rupture utilizing a similar "Knickerbocker technique" (19). We have previously presented our approach to chronic thoracoabdominal aortic dissection with our decision algorithm (14) (Figure 2). In the current study we have employed more frequent use of BFF technique, $65 \%$ prior to FLE procedure and $24 \%$ concomitantly, compared to only $5 \%$ of patients in our previous FLE series. This is a result of BFF more often being performed at the time of initial TEVAR stenting to obliterate the false lumen and prevent retrograde false lumen flow. In those instances when this is not achieved, and the patient is higher risk open thoracoabdominal repair, subsequent endovascular reintervention with FLE is performed. In select patients that are higher risk for open thoracoabdominal repair with poor distal landing zone $(>4 \mathrm{~cm})$, we may perform TEVAR extension with BFF and FLE simultaneously.

Increasingly we have begun supporting the true lumen of the abdominal aorta with a commercially available bare metal dissection stent (Zenith, Cook Medical, Bloomington IN, USA) utilizing it in $53 \%$ of patients in this study. This strategy has predominantly been studied in complicated acute dissections with promising results $(20,21)$. In chronic dissections we use it to stabilize and reinforce true lumen expansion, particularly when BFF is performed proximally through the stent grafted descending thoracic aortic segment (15). We have elected not to balloon the bare stented portion of the aorta through the abdominal aorta 
to avoid potential malperfusion of branch vessels arising from the false lumen. Faure and colleagues reported 88\% false lumen thrombosis and cessation of aortic growth in a population of chronic dissection patients with a similar technique that also includes ballooning through the abdominal aorta after deployment of a bare metal dissection stent (22). Not surprising, however, is the observation that renal and/or iliac arteries arising from the false lumen required stenting to maintain perfusion in $53 \%$ of those study patients.

The limitations of this study are its retrospective singleinstitution design and small sample size. Follow-up has been short-term but the reasonable outcomes observed after refinement of our patient selection and surgical technique warrant continued application of these strategies and further long-term study.

\section{Conclusions}

False lumen embolization as an adjunct to descending TEVAR with concomitant descending aortic balloon fracture fenestration and extension of bare metal stenting through non-aneurysmal true lumen are viable strategies to obliterate the false lumen in chronic dissection. In the appropriately selected patient, these interventions are safe and may facilitate positive aortic remodeling.

\section{Acknowledgments}

Funding: None.

\section{Footnote}

Conflicts of Interest: PRV speaks for Edwards Lifesciences and is a consultant for Cryolife. EER is a consultant and speaker for Cook Medical, Cryolife, Edwards Lifesciences, Gore, Medtronic, and Terumo Aortic. The other author has no conflicts of interest to declare.

Open Access Statement: This is an Open Access article distributed in accordance with the Creative Commons Attribution-NonCommercial-NoDerivs 4.0 International License (CC BY-NC-ND 4.0), which permits the noncommercial replication and distribution of the article with the strict proviso that no changes or edits are made and the original work is properly cited (including links to both the formal publication through the relevant DOI and the license). See: https://creativecommons.org/licenses/by-nc-nd/4.0/.

\section{References}

1. Roselli EE. Thoracic endovascular aortic repair versus open surgery for type-B chronic dissection. J Thorac Cardiovasc Surg 2015;149:S163-7.

2. Spanos K, Kölbel T, Rohlffs F, et al. Intentional Targeted False Lumen Occlusion after Aortic Dissection: A Systematic Review of the Literature. Ann Vasc Surg 2019;56:317-29.

3. Kusagawa $\mathrm{H}$, Shimono T, Ishida $M$, et al. Changes in false lumen after transluminal stent-graft placement in aortic dissections: six years' experience. Circulation 2005;111:2951-7.

4. Nienaber CA, Rousseau H, Eggebrecht $\mathrm{H}$, et al. Randomized comparison of strategies for type B aortic dissection: the INvestigation of STEnt Grafts in Aortic Dissection (INSTEAD) trial. Circulation 2009;120:2519-28.

5. Tanaka A, Sakakibara M, Ishii H, et al. Influence of the false lumen status on clinical outcomes in patients with acute type B aortic dissection. J Vasc Surg 2014;59:321-6.

6. Subramanian S, Roselli EE. Thoracic aortic dissection: long-term results of endovascular and open repair. Semin Vasc Surg 2009;22:61-8.

7. Kang WC, Greenberg RK, Mastracci TM, et al. Endovascular repair of complicated chronic distal aortic dissections: intermediate outcomes and complications. J Thorac Cardiovasc Surg 2011;142:1074-83.

8. Li D, Ye L, He Y, et al. False Lumen Status in Patients With Acute Aortic Dissection: A Systematic Review and Meta-Analysis. J Am Heart Assoc 2016;5:003172.

9. Kamman AV, Jonker FHW, Sechtem U, et al. Predictors of Stable Aortic Dimensions in Medically Managed Acute Aortic Syndromes. Ann Vasc Surg 2017;42:143-9.

10. Lombardi JV, Hughes GC, Appoo JJ, et al. Society for Vascular Surgery (SVS) and Society of Thoracic Surgeons (STS) Reporting Standards for Type B Aortic Dissections. Ann Thorac Surg 2020;109:959-81.

11. Coselli JS, LeMaire SA, Preventza O, et al. Outcomes of 3309 thoracoabdominal aortic aneurysm repairs. J Thorac Cardiovasc Surg 2016;151:1323-37.

12. Pujara AC, Roselli EE, Hernandez AV, et al. Open repair of chronic distal aortic dissection in the endovascular era: Implications for disease management. J Thorac Cardiovasc Surg 2012;144:866-73.

13. Vivacqua A, Idrees JJ, Johnston DR, et al. Thoracic endovascular repair first for extensive aortic disease: the staged hybrid approach†. Eur J Cardiothorac Surg 
2016;49:764-9.

14. Miletic KG, Kindzelski BA, Hodges KE, et al. Impact of Endovascular False Lumen Embolization on Thoracic Aortic Remodeling in Chronic Dissection. Ann Thorac Surg 2021;111:495-501.

15. Levack MM, Kindzelski BA, Miletic KG, et al. Adjunctive endovascular balloon fracture fenestration for chronic aortic dissection. J Thorac Cardiovasc Surg 2020. [Epub ahead of print]. doi: 10.1016/j.jtcvs.2020.09.106.

16. Kim TH, Song SW, Lee KH, et al. Effects of False Lumen Procedures on Aorta Remodeling of Chronic DeBakey IIIb Aneurysm. Ann Thorac Surg 2016;102:1941-7.

17. Pellenc Q, Roussel A, De Blic R, et al. False lumen embolization in chronic aortic dissection promotes thoracic aortic remodeling at midterm follow-up. J Vasc Surg 2019;70:710-7.

18. Yuan X, Mitsis A, Semple T, et al. False lumen intervention to promote remodelling and thrombosis-The FLIRT

Cite this article as: Vargo PR, Maigrot JL, Roselli EE. Chronic thoracoabdominal aortic dissection: endovascular options to obliterate the false lumen. Ann Cardiothorac Surg 2021;10(6):778-783. doi: 10.21037/acs-2021-taes-23 concept in aortic dissection. Catheter Cardiovasc Interv 2018;92:732-40.

19. Kölbel T, Carpenter SW, Lohrenz C, et al. Addressing persistent false lumen flow in chronic aortic dissection: the knickerbocker technique. J Endovasc Ther 2014;21:117-22.

20. Lombardi JV, Cambria RP, Nienaber CA, et al. Fiveyear results from the Study of Thoracic Aortic Type B Dissection Using Endoluminal Repair (STABLE I) study of endovascular treatment of complicated type B aortic dissection using a composite device design. J Vasc Surg 2019;70:1072-81.e2.

21. Melissano G, Bertoglio L, Rinaldi E, et al. Satisfactory short-term outcomes of the STABILISE technique for type B aortic dissection. J Vasc Surg 2018;68:966-75.

22. Faure EM, El Batti S, Sutter W, et al. Stent-assisted balloon dilatation of chronic aortic dissection. J Thorac Cardiovasc Surg 2021;162:1467-73. 